\title{
AS RELAÇÕES ENTRE A OBRA DE OSCAR WILDE E O CENÁRIO INGLÊS DO FINAL DO SÉCULO XIX: CRÍTICAS E INFLUÊNCIAS NA ERA VITORIANA; A IDENTIDADE E A ARTE BURGUESA
}

\section{THE RELATIONS BETWEEN OSCAR WILDE'S WORD AND THE ENGLISH SCENERY AT THE END OF THE 19TH CENTURY: CRITICISM AND INFLUENCES AT THE VICTORIAN PERIOD; IDENTITY AND BOURGEOIS ART}

Resumo: O presente trabalho busca, juntamente com uma análise histórica do contexto britânico do final século XIX, discutir as múltiplas correntes de pensamento vigentes na era vitoriana, como o decadentismo e o hedonismo, presentes na obra de Oscar Wilde $O$ retrato de Dorian Gray, publicada pela primeira vez em 1891, cristalizando os momentos em que os pensamentos do período se alinham, muitas vezes de forma sutil, às narrativas dos personagens. Este artigo objetiva estabelecer relações entre um período marcado pelo avanço científico e industrial, pela polaridade social inglesa - pessoas muito pobres ou muito ricas -, as múltiplas concepções acerca do que seria a arte, a formulação de uma individualidade burguesa, as representações desse contexto histórico e as teorias nele presentes abordadas na narrativa de Wilde.

Palavras-chave: Oscar Wilde, O Retrato de Dorian de Gray, Hedonismo, Decadentismo, Arte Burguesa, Era Vitoriana.

Abstract: The present article tries, along with a historical analysis of the British context at the end of the 19th century, to discuss the multiple

\footnotetext{
${ }^{1}$ Graduanda em História (Licenciatura e Bacharelado) pela Universidade Federal do Paraná. Email para contato: victorialucena16@gmail.com. Endereço para o currículo Lattes: http://lattes.cnpq.br/2126978861757559.
} 
streams of thought common to the Victorian Period, such as the decadent movement and the hedonism, present in Oscar Wilde's The Picture of Dorian Gray, published for the first time in 1891, illustrating the moments in which the period's thoughts align, many times in a subtle way, to the characters' narrative. This article objectives to establish relations between a period marked by scientific and industrial progress, as well as social polarity - very rich or very poor people -, the multiple conceptions about the meaning of art, the formulation of a bourgeois individuality, the representations of this historical period and the theories within it, approached by Wilde in his narrative.

Key-words: Oscar Wilde, The Picture of Dorian Gray, Hedonism, Decadent Movement, Bourgeois Art, Victorian Period.

\section{Introdução}

Oscar Wilde nasceu em 1854 em Dublin, na Irlanda, filho de um médico com uma poetisa nacionalista, que escrevia por meio do pseudônimo Speranza. Wilde iniciou a divulgação do Movimento Nova Estética, ou a Arte pela Arte quando começou os estudos em Magdalen College em Oxford. Diante da ausência de uma bolsa de estudos em Oxford, o escritor, a fim de ganhar a vida, começa a dar aulas e a escrever na imprensa. Em 1882, inicia uma sucessão de palestras nos Estados Unidos para promover a companhia D'Oyle Cate, da ópera-cômica Patience, de Gilbert e Sullivan. Wilde casou-se em 1884 com Constance Lloyd e, em seguida, buscou se estabelecer como escritor, porém não obteve muito êxito. Todavia, paulatinamente foi adquirindo o status de escritor moderno com os três breves volumes de ficção $O$ príncipe feliz (1888), O crime do lord Arthur Savile (1891), A casa das romãs (1891) e,

principalmente, com seu único romance $O$ retrato de Dorian Gray (1891). 
Suas comédias sociais também contribuíram para reforçar seu sucesso: $O$ leque de Lady Windermere, Uma mulher sem Importância, Um marido ideal e a importância de ser prudente. Apesar disso, o sucesso do escritor foi breve. Quando estava em seu auge, Wilde processou o marquês de Queensbarry, pai de Lord Alfred Douglas - jovem por quem Oscar Wilde se apaixonou em 1891 - por difamação, perdendo a ação e posteriormente sendo condenado à reclusão por atos de flagrante indecência. Em liberdade no ano de 1897, se exilou no continente e morreu na miséria em 1900.

A obra de Oscar Wilde se ambienta na Inglaterra, no século XIX, em plena Era Vitoriana - um período em que os valores morais pautavam a sociedade, em que a figura feminina deveria possuir um caráter de passividade e em que se prezava um valor pela disciplina do "eu", atentando para o comportamento dos indivíduos e ao modo como esses percebiam o religioso, especialmente no que diz respeito às classes mais abastadas. Outro ponto de relevância nesse contexto é a situação de pobreza vivida pelas classes mais baixas, os trabalhadoresestavam sujeitos concomitante a longas jornadas de trabalho - incluindo o trabalho infantil -, prostituição, ausência de benefícios sociais e comércio de drogas. Apesar desse cenário, o período foi marcado por um intenso crescimento artístico, cultural, filosófico, científico e industrial. Uma época em que os comportamentos e pensamentos, paulatinamente, estavam se transformando.

De acordo com Rezende (2017: 26) diante do processo de industrialização que avançava em terras britânicas, a Inglaterra foi se 
fixando como o centro econômico e financeiro do mundo, juntamente com as ações imperialistas, que agiam como uma mola propulsora do progresso e da política. O avanço da maquinaria, as descobertas científicas, assim como os tratados de Darwin, que promoveram uma revolução na ciência e na crença da evolução das espécies, e o avanço tecnológico e da indústria auferem ao Reino Unido a posição de centro do mundo moderno, simultaneamente a um sentimento, no cidadão britânico, de pertença a uma nação que se distinguia das outras. Desta forma, configura-se uma moral e valores puritanos e/ou vitorianos que guiarão a conduta dos bons cidadãos. Destarte, era uma sociedade que, apesar dos valores empregados, possuía grandes imperfeições, a exemplo de uma sociedade dividida entre os bem-nascidos e as áreas marginalizadas. Diante do crescimento desenfreado e sem planejamento, houve um deslocamento de pessoas em direção a Londres em busca de novas oportunidades, resultando em uma saturação populacional, e, por conseguinte, em uma crise social, afastando as classes mais pobres dos bem-nascidos. Uma vez que, como aponta Rezende (2017: 21-27), essas classes mais baixas encontravam-se sem emprego e sem perspectivas, esses indivíduos foram colocados como a escória da sociedade inglesa do século XIX, restando-lhes a criminalidade e a prostituição. Diante do exposto, a manifestação do Decadentismo na literatura Inglesa nesse período, em virtude do cenário social conflituoso, ilustra, além das angústias da época, a postura transgressora dos homens em relação à sociedade. 
É nesse contexto que Oscar Wilde escreve sua obra, influenciado pelas movimentações e pensamentos da época que questionam, direta ou indiretamente, o comportamento social que condiciona o sujeito às normas e valores vitorianos, buscando ressalvar a individualidade do homem, o qual muitas vezes não compartilhava da normativa social empregada.

A obra de Wilde, publicada em 1891, em um primeiro momento não obteve uma boa recepção pelos críticos, uma vez que continha insinuações homossexuais e valorização ao hedonismo. Todavia, segundo Quadros Zamboni (2017: 99), o autor alega que os críticos não compreenderam o verdadeiro sentido da arte, a qual deveria ser analisada apenas pelo seu teor estético, sem julgamentos de valor. É importante destacar, dessa forma, a influência do movimento $A$ arte pela arte na construção da obra de Oscar Wilde, $O$ retrato de Dorian Gray ${ }^{2}$.

\section{As relações entre a obra de Oscar Wilde e o cenário inglês do final do século XIX: Críticas e influências na Era Vitoriana; a identidade e a arte burguesa}

O século XIX foi marcado, para além de outros elementos, pela formulação das filosofias da História, as quais buscavam dar sentido ao cenário de caos em que se encontrava a sociedade, caminhando para um progresso. Todavia, o período não se restringe a um único pensamento, no

${ }^{2} O$ retrato de Dorian Gray narra a história de um jovem gentleman inglês da Era Vitoriana que, na ânsia pela eterna juventude e beleza, vende sua alma, envolto a uma sociedade decadente, fundamentada em uma hipocrisia moral. O narcisismo, o hedonismo e a valorização do "eu" são elementos que permeiam a história do jovem que se torna reflexo dessa sociedade. 
sentido em que haverá nesse século ideias e pensamentos que compartilham e criticam as teorias das filosofias da história, as quais também possuem multiplicidades. O romantismo, nesse sentido, surge como corrente de principal crítica frente a essas teorias. Logo,

Não havia apenas dúvidas invadindo a fé no progresso. Contrastando com aquela fé que encontramos definida como "a fé do nosso século" no dicionário Larousse (edição de 1875) e que consiste em crer que a humanidade passa incessantemente do bom para o melhor, da ignorância para a ciência, da barbárie para a civilização, havia as milhares de páginas escritas por filósofos, psiquiatras, antropólogos, sociólogos, jornalistas e romancistas (entre os quais o supracitado Émile Zola) sobre o tema da degeneração. A propósito do qual, escreveu o autor de Faces of Degeneration, traçando a história de uma desordem europeia entre 1848 e 1918; "a potencial degeneração da sociedade europeia não era discutida como se constituísse um problema religioso ou ético ou filosófico, mas como um fato médico, biológico ou antropológico empiricamente demonstrável (ROSSI, 2000: $123)$.

Assim, há uma heterogeneidade de pensamentos nesse período, que será apresentada em diversas narrativas, mas é nos romances que a visualização dessas divergências, teóricas e sociais, serão explícitas. Assim o "tema do romance será a fuga do mundo, o desprezo pelas normas convencionais, em um cosmos autocontido e artificial, no qual a flor da estufa decadentista pode florescer" (TAVARES, 2016: 83). Desta forma, a obra de Wilde retrata essa heterogeneidade de pensamentos e posturas em 
meio ao cenário inglês de fortes conturbações de uma sociedade decadente. Nesse sentido, tais aspectos são trazidos à luz na obra de Wilde pelos personagens do pintor Basil Hallward, pelo Lorde Henry Wotton e pelo jovem Dorian Gray - uma tríade que representaria a personalidade do próprio autor (TAVARES, 2016: 86).

É importante destacar que, simultaneamente a esse contexto, os valores e a cultura burguesa vão se consolidando e se afirmando por meio da construção do espaço privado. O romance e o retrato - elemento de destaque na obra de Wilde -, logo a arte burguesa, são por excelência sua expressão cultural. Uma cultura que se volta para sua intimidade e para a representação do "eu". Basil Hallward ilustra esse fenômeno no momento que, ao ser indagado por Lorde Henry Wotton se iria expor a pintura que fizera de Dorian Gray, afirma que não, pois nela continha a alma do pintor:

Todo retrato pintado compreensivamente é um retrato do artista, não do modelo. O modelo é puramente o acidente, a ocasião. Não é ele revelado pelo pintor; é antes o pintor quem se revela na tela colorida. A razão que me impede de exibir esse quadro consiste no terror de, por meio dele, patentear o segredo de minha alma! (WILDE, 2016: 17).

Assim, em paralelo com a consolidação da burguesia, tem-se a busca pela construção de uma identidade e de uma personalidade concomitante a uma personalidade coletiva, social Vitoriana. Nesse sentido, Sennett (1998: 192-193) discorre que, no século XIX, a personalidade diferia da visão iluminista, uma vez que a personalidade é vista como um elemento que 
varia de pessoa para pessoa - uma visão contrária à perspectiva do século XVIII, a qual, pelo caráter natural, a compreendia como um laço comum a toda espécie humana. Todavia, a personalidade moderna diverge da ideia de caráter natural no fato de que a liberdade de sentir um determinado momento parece ser uma violação do sentimento convencional "normal". Assim, a espontaneidade da personalidade coloca-se em oposição à convenção social.

No concernente à obra de Oscar Wilde, sua produção coloca o autor na mesma esfera dos indivíduos considerados imorais de acordo com os valores da sociedade vitoriana. O personagem Henry Wotton cristaliza a crítica do autor a essa sociedade - fazendo em diversos momentos o uso da sátira -, e sua estrutura utilitária e moralizante, sendo associado à falta de moral, inclusive dentro do romance (TOFFOLI, 2013: 20-28). Uma crítica que pode ser visualizada na fala de Wotton:

o fim da vida é o desenvolvimento da personalidade. Realizar a sua própria natureza, eis o que todos procuramos fazer. Os homens amedrontam-se deles mesmos. Esqueceram-se do maior de todos os deveres, do dever que cada um deve a si próprio. Naturalmente são caridosos. Nutrem o pobre e vestem os andrajosos, mas deixam suas almas famintas e andam nus.[...] o terro da sociedade, que é a base de toda a moral, o terror de Deus, que é o segredo da religião, eis as duas coisas que nos governam (WILDE, 2016: 29-30).

É essa personalidade de Lord Wotton, baseada na fé pela ciência - e não mais no religioso -, na filosofia de vida baseada no hedonismo e na 
crítica dos valores morais da sociedade vitoriana, que influenciará a figura de Dorian Gray à realização de ações condenáveis perante a sociedade, e que, por conseguinte, culminariam na degradação de sua alma. Uma influência retratada em diversos momentos do romance: "Tu me enchestes do ardente desejo de tudo saber da vida" (WILDE, 2016: 60). O hedonismo de Henry será um dos elementos de destaque do romance, sendo o jovem Dorian Gray sempre incitado a praticá-lo, pelo amigo. Logo, “o adolescente era de algum modo, sua própria criação.” (WILDE, 2016: 69).

A filosofia hedonista busca a defesa e aquisição de uma vida fundamentada no prazer, sendo ele o maior objetivo da existência. No momento em que Dorian visualiza a pintura que Basil fez de sua pessoa, toma consciência de sua beleza, e teme perdê-la, assim como perderia a juventude. Um sentimento incitado e potencializado pela figura de Lorde Henry, quando profere que o jovem possui uma beleza e juventude que colocam em sua posse o mundo, ainda que por um tempo limitado, assim como sua juventude, pois chegará um momento em que não as terá mais. Assim, Henry, fundamentado por sua filosofia de vida, sugere de maneira imperativa, que Dorian

Viva! Viva a maravilhosa vida de que dispõe! Não queira perder nada! Busque sempre novas sensações! Nada receie... Um novo hedonismo, eis o que pede esse século. O símbolo visível está em ti. [...] O mundo é seu por algum tempo! (WILDE, 2016: 34). 
Desta forma, o jovem Dorian busca viver influenciado por esses preceitos, explorando as mais diversas sensações possíveis, de forma a levar-se mais à frente em direção às ações que divergiam do moralmente indicado. A beleza de Dorian é, então, o ponto de partida para a construção da narrativa, uma vez que, para Wilde, a arte é a busca pela beleza, havendo em sua obra uma constante discussão sobre o que seria a arte (TOFFOLI, 2013: 28) e qual seria sua relação com a beleza, e dentro dessa discussão encontra-se Dorian Gray, como materialização. Ainda no que se refere às discussões sobre a arte, a figura de Basil, ao alegar que a arte revelaria seu realizador, é colocada pelo autor como a personagem digna de questionamentos, pois a arte, na visão do autor, não deveria revelar nada mais do que ela mesma. Assim sendo, o decadentismo também se encontra no contexto cultural inglês do XIX, principalmente a partir do final do século e, por conseguinte, na produção de Wilde. Essa corrente artística consiste em ilustrar a presença de um mundo em ruínas e de um ambiente caótico e decadente, ao passo que busca o resgate do "eu”, reivindicando uma individualidade que se perdera há muito, em virtude do contexto burguês de uniformização do operariado do século XIX (REZENDE, 2017: $40,51)$. Uma crítica que pode ser exemplificada por Lowy, ao afirmar que todas as pessoas eram semelhantes umas às outras, e que o espaço parecia ter perdido toda sua diversidade qualitativa e toda variedade cultural, tornando-se uma estrutura única (LÖWY, SAYRE; 2015: 60). Na busca pelo seu "eu" perdido, o qual fora condicionado a uma polidez moralista, 
Dorian, alinhando-se ao hedonismo, não desprezará experiência alguma, como sugerida por Lorde Henry.

No concernente à constante busca pela arte, é nesse elemento que outros personagens se inserem na obra, a exemplo da jovem Sibyl Vane. Já em caminhos que não são muito bem vistos pela sociedade, buscando prazeres, Dorian Gray frequenta espaços londrinos que um jovem de sua classe não deveria adentrar e encontra um teatro em que a jovem Sibyl atua. De imediato é tomado por uma paixão, tanto pela beleza ingênua da moça quanto pela sua percepção de arte, nela cristalizada. A relação de Dorian com a jovem atriz é o ponto inicial para a representação da mudança vivida pelo protagonista do romance. Apesar de o jovem ter jurado amor e casamento à Sibyl, ele ao ter sua representação de arte atacada em um momento em que a atriz não atua bem, a renega sem piedade e de maneira cruel, o que culmina no suicídio da moça. Diante disso, pode-se dizer que é o momento em que o interior de Dorian se modifica, pois é a partir desse episódio que há a primeira alteração na pintura feita por Basil Hallward.

[...] a face the pareceu um pouco mudada... A expressão revelava-se diferente. Dir-se-ia que ali havia como um toque de crueldade na boca, $[. .$.$] como se ele próprio, após haver$ praticado qualquer coisa horrível, as descobrisse em sua face, num espelho. [...] $\mathrm{O}$ retrato ali estava diante dele, mostrando na boca um arrepanho de crueldade (WILDE, 2016: 104-105). 
Dessa forma, seu desejo, enunciado quando viu sua pintura, de manter-se jovem, enquanto o quadro envelheceria, se concretiza. Assim, as ações corrompidas do jovem seriam cada vez mais frequentes e, por conseguinte, visíveis em sua pintura, uma vez que "esta estava transformada e ainda se alteraria", pois a "cada pecado que ele cometesse, nova mancha se juntaria às outras, empanando-lhe pouco a pouco a beleza... Ele, porém, não pecaria, e o retratado, se alterando ou não, refletiria as ações de sua alma”(WILDE, 2016: 106). Logo, “a eterna mocidade, a infinita paixão, os prazeres sutis e secretos, as alegrias ardentes e os pecados ainda mais ardentes - tudo ele deveria conhecer. $\mathrm{O}$ retrato conservaria o peso de sua vergonha - e eis tudo" (WILDE, 2016: 119).

Diante do exposto, um elemento que se apresenta em diversos momentos da narrativa, ora de maneira sutil, ora não, diz respeito ao narcisismo de Dorian Gray. É perceptível a semelhança com o mito de Narciso, no sentido em que a ninfa Eco - na obra, representada por Silbyl -, quando rejeitada por Narciso, morre de desgosto, e o jovem é punido pelos deuses, de maneira a se apaixonar por sua própria imagem (MARIANI, 2008: 4). O mito de Narciso representa uma das diversas referências à cultura clássica presente no romance de Wilde, ilustrando, pela forma de linguagem das personagens de uma classe social alta, a presença de uma erudição, no século XIX, que remete a uma formação cultural influenciada pelos clássicos. A ausência de sentimento, como traço significativo do narcisismo, é representado ao longo da obra, gradualmente, por meio das 
ações de Dorian, a exemplo da falta de sensibilidade em um segundo momento pela morte de Sibyl e, posteriormente, ao assassinar Basil. A ação do narcisista como espectador de si é outra chave para a representação de Dorian. Trata-se, nas palavras de Sennett, de um "auto-interesse esclarecido" (SENNETT, 1998: 272). Assim, "dias e dias, ele se colocaria diante de seu retrato, maravilhando-se da própria beleza, quase enamorado dela, como muitas vezes lhe pareceu" (WILDE, 2016: 119).

Ao longo da narrativa e da deterioração da alma de Dorian, representada pela pintura, a figura feminina é apresentada quase sempre de maneira pejorativa, mesmo quando descrita conforme as expectativas da sociedade vitoriana. Afinal, ela sempre estaria suscetível à corrupção, que, na visão de Dorian Gray, maculava, paulatinamente, sua alma, atrelada ao retrato. No momento em que o jovem toma consciência de sua degradação, visualizada em seu retrato pela figura de um homem que contém, para além da marca do tempo, as manchas de uma vida repleta de corrupções, que outrora eram vistas de maneira positiva, busca dar um fim nas angustias e frustações em que se encontra, uma vez que suas tentativas de restaurar sua alma se tornam frustradas. Diante do fracasso dessa tentativa e o tormento pelo qual foi tomado, em virtude da visualização de suas ações e, assim, de sua alma, Dorian, ao fitar o punhal com o qual assassinou Basil - seu maior e fiel admirador, que sempre buscou manter em Dorian a pureza e beleza -, põe fim a uma trajetória que almejou aos mais diversos prazeres, apunhalando o retrato feito por Basil. 
Como havia exterminado o pintor, assim exterminaria a sua obra e tudo quanto ela significava... Exterminaria o passado, e quando esse passado estivesse morto estaria livre!... aniquilaria o monstruoso retrato de sua alma e, livre de suas medonhas advertências, recobraria a paz. Agarrou o punhal e apunhalou o quadro! (WILDE, 2016: 244).

Diante do grito dado ao apunhalar o retrato, os criados adentram o sótão, onde a pintura estivera guardada desde o início de sua degradação, e encontraram o retrato de Dorian Grey, tão belo jovem como de início, e um homem velho com marcas repulsivas, caído no chão.

\section{Considerações finais}

A obra de Oscar Wilde $O$ retrato de Dorian Gray perpassa diversas temáticas pertinentes à sociedade inglesa do século XIX. Dando maior enfoque para alguns elementos, como a crítica a uma sociedade inglesa moralista, vista como a mais rica e livre, em virtude de uma industrialização cada vez mais forte, apresenta sintomas de uma nação que sofre com grandes desordens internas, como um aumento populacional, extremos de riqueza e pobreza, aumento de uma marginalidade (roubos, prostituição e mendicância), entre outros elementos (FONTANA, 2004: 204). Também destaca a construção e a busca por uma valorização do "eu", uma discussão que permeia todo o século XIX, ao que concerne a formação de uma identidade burguesa. Nesse sentido, a presença do retrato e do romance em si, ambos tidos como expressividade da essência dessa cultura burguesa, torna possível a percepção de diversos elementos já consolidados 
no final do século XIX, quando se produz a obra de Wilde. Outros aspectos desse contexto são trazidos à tona na obra, de maneira mais natural, como o nacionalismo, as relações entre Inglaterra e suas colônias, a presença dos saberes clássicos na erudição burguesa, para além de outros temas. Trazidos como fenômenos simultâneos à narrativa, tais aspectos encontram-se no cotidiano de uma sociedade e de um povo. $\mathrm{O}$ romance permite uma compreensão do cotidiano e dos sentimentos de uma nação em determinado contexto histórico social, uma vez que a história, apesar de iniciar sua consolidação como ciência, preocupa-se com aquilo que se tinha como oficial, o Estado. Por fim, é importante destacar que a obra de Oscar Wilde não possui, necessariamente, assim como o movimento romântico, uma única crítica, sendo sua obra, assim como o movimento, repleto de contradições e complexidades.

\section{Referências}

FONTANA I LAZARO, Josep. Marx e o Materialismo Histórico. In: $A$ história dos homens. Tradução de Heloisa Jochims Reichel e Marcelo Fernando Da Costa. São Paulo: EDUSC, 2004.

LÖWY, Michael; SAYRE, Robert. Revolta e melancolia. São Paulo: Boitempo, 2015.

MARIANI, Sérgio Luis Soares. Dorian Gray: um retrato do narcisismo sob a ótica de Alexander Lowen. In: ENCONTRO PARANAENSE, XIII; CONGRESSO BRASILEIRO, VIII; CONVENÇÃO BRASIL/LATINO-AMÉRICA, II, 2008, Curitiba. Anais Eletrônicos. Curitiba: Centro Reichiano, 2008. 
QUADROS-ZAMBONI, Alessandra. da Silva. Não existem livros morais ou imorais: hedonismo, subjetividade e sociedade em $\mathrm{O}$ retrato de Dorian Gray. Revista Versalete, Curitiba, v. 5, n. 8, p. 97-108, jan./jun. 2017.

REZENDE, Sabrina Mesquita de. O entre-fronteiras decadentista de Drácula e O retrato de Dorian Gray. 2017. 118 f. Dissertação (Mestrado em Estudos da Linguagem) - Universidade Federal de Goiás, Catalão, 2017.

ROSSI, Paolo. Naufrágios sem espectador: A ideia de progresso. São Paulo: Unesp, 2000.

SENNETT, Richard. $O$ declínio do homem público: as tiranias da intimidade. São Paulo: Companhia das Letras, 1998.

TAVARES, Enéias Farias. Esteticismo e decadentismo nos dândis de Wilde e Huysmans: retratos de Des Esseintes e Dorian Gray. Acta Scientiarum Language and Culture. Maringá, v. 38, n. 1, p. 79-91, jan./mar. 2016.

TOFFOLI, Tânia. O retrato de Dorian Gray: um romance em três tempos circulação entre Inglaterra e Brasil. 2013. 179 f. Dissertação (Mestrado em Teoria e História Literária) - Instituto de Estudos da Linguagem, Universidade Estadual de Campinas, Campinas (SP), 2013.

WILDE, Oscar. O retrato de Dorian Gray. Tradução de João do Rio. São Paulo: Ed. Martin Claret, 2016. 